\title{
Implementing 'real' change: a Bourdieusian take on stakeholder reflections from the United Nations Partnership on the Rights of Persons with Disabilities project in Uruguay
}

\author{
Holly Wescott ${ }^{1}$ D $\cdot$ Mac MacLachlan ${ }^{1}$
}

Received: 13 April 2021 / Accepted: 21 October 2021 / Published online: 22 November 2021

(c) The Author(s) 2021, corrected publication 2021

\begin{abstract}
This study aims to illustrate the process of implementing a national disability project targeting structural change facilitated by the United Nations Partnership on the Rights of Persons with Disabilities (UNPRPD), and analysed through the theoretical lens of Pierre Bourdieu. This paper presents qualitative case study findings from interviews with key representatives from the UNPRPD country project in Uruguay in 2019. Participant responses were coded and analysed using Bourdieu's definitions of field, doxa, capital, habitus and hysteresis as a framework to understand complex inter-institutional experiences. Findings indicate a significant shift in cultural capital within government ministries and United Nations agencies. Immersion into a paradigm of disability rights and programmatic doxa established by the UNPRPD altered fundamental aspects of participant habitus, creating a mismatch between internal and environmental conditions. Furthermore, shifts in political power created concerns about what constitutes 'real' change, and increased the disruption between habitus and perceptions about the UNPRPD project achievements.
\end{abstract}

Keywords Bourdieu · Disability · International development · Hysteresis · Uruguay

Holly Wescott

holly.wescott.2019@mumail.ie; hollywescott@gmail.com

Mac MacLachlan

Mac.MacLachlan@mu.ie

1 Department of Psychology and the Assisting Living \& Learning (ALL) Institute, Maynooth University, Maynooth, Ireland 


\section{Introduction}

Disability rights have been a growing development consideration, particularly, since the United Nations Convention on the Rights of Persons with Disabilities (CRPD) entered into force in 2007 and the World Bank (WHO \& World Bank 2011) reported approximately $15 \%$ of the world's population having one or more disabilities. Global recognition of the historic and persisting exclusion of persons with disabilities was a significant shift in perceptions of disability. Constructions of disability are commonly framed in the medical and social models. The medical model understands disability as an individual deficit that requires intervention (e.g. cochlear implants and speech therapy for D/deaf people) to fit 'normal' social expectations, whereas the social model recognises the diversity of human beings excluded through barriers in the build environment (e.g. buildings without ramps, policies for institutionalisation, absence of alt text in digital images) that have systematically excluded people with disabilities (Shakespeare 2014). People with disabilities were once seen as a small group invisible to the majority. Now international treaties set out global calls for rights on behalf of disabled people and other marginalised groups.

Much of the CRPD mandates more than reducing physical barriers such as installing a ramp or elevator, but also deconstructing the ideologies and abstract barriers that perpetuate the discrimination of persons with disabilities in spite of previous efforts to improve accessibility. The United Nations established a joint programme to support countries navigating the complexity of disability development, comprised of various UN entities (nine participating agencies at the time of this study, including ILO, OHCHR, UNDESA, UNDP, UNESCO, UNFPA, UNICEF, UN Women and WHO) into the Partnership on the Rights of Persons with Disabilities (UNPRPD) (United Nations Development Program [UNDP] 2016). The barriers addressed in UNPRPD programming target established norms expressed through policies, practices, attitudes and beliefs about individual capacity maintained over generations, and are very difficult to reform. Changing the fundamental assumptions on which the structure of our societies is based will help to create a ripple effect. For example, reforming the way in which people with disabilities are educated will likely impact employment, civic participation, healthcare and other central structures extending from improved access to education. The UNPRPD approach to implementing the CRPD aims to address these underlying barriers across multiple contexts, thereby triggering structural change beyond a contained, predetermined development scheme.

The structural change initiated by UNPRPD country projects are diverse in their approaches to realising disability rights in local contexts, offering valuable experience and insight into how this global issue can be addressed. Sociologist, Pierre Bourdieu, provides a framework to make sense of the UNPRPD initiative and disability inequity, as well as methods to express structural changes in complex organisational systems. The study below applies Bourdieu's research methodology to explore the UNPRPD mechanism from the United Nations Country Team (UNCT) perspectives in Uruguay during the first phase of programme implementation. 
The UNPRPD Theory of Change (ToC) follows a tripartite framework, engaging the United Nations, government ministries and civil society organisations (with particular emphasis on Organisations of Persons with Disabilities; OPDs; previously called Disabled Persons Organisations or DPOs) (UNDP 2016). By bringing entities together that historically work independently, the UNPRPD takes the strengths and expertise from multiple UN agencies, diverse government ministries and the representative organisations of persons with disabilities into human rights development. As of 2020, the UNPRPD has supported 39 country projects, 3 regional projects and 7 global programmes (UNPRPD 2019).

\section{Bourdieu and the UNPRPD}

Bourdieusian theories have been used to describe a number of social inequalities, including disability (Bryne 2018; Edwards and Imrie 2003; Blackmore and Hodgkins 2012) and situations of international development (Krause 2014, 2017); however, they have rarely been used together. Bourdieu's theories focus on the systems level and how structures interact in context (Bourdieu 1987). Each level (macro and micro) is inseparable, whereby either structure or agent always leads back to the other, and therefore must be seen as a whole.

Bourdieu describes marginalisation at the systems level and how structural barriers are embedded in individuals (habitus), reinforcing exclusion through practice as social norms (Bourdieu 1984, 1986). Structures at the hierarchical top are held in place by disproportionate resources such as knowledge, social networks, status and economic stability (capital), whereas exclusion occurs when those resources have been historically withheld (Bourdieu 1986). The UNPRPD looks to trigger these underlying forces (capital) that perpetuate exclusion at the structural level, making Bourdieu a natural fit to ground the findings in a systematic context.

Bourdieu's theories encompass several key concepts valuable for understanding disability development locally and globally, including doxa, fields, capital, habitus and hysteresis. First, the idea of everyday norms and assumptions or doxa (Bourdieu 1977 ) is important to explore the way structural processes are practiced by individuals in their social 'bubbles' that perpetuate inclusion or exclusion. Doxa describes shared logics that have become institutionalised as automatic or natural practices (Bourdieu 1977, 1998). These practices are constrained to their contexts, making various doxa unique unto themselves. Doxa is a common consideration for international development because a successful intervention in one country may not translate to another. Local experts, such as community members or civil society organisations, can help ameliorate the consequences of development in unfamiliar settings by bringing local logics to development projects. The norms and conventions, or 'rules of the game' according to Bourdieu, are practices developed and fixed by repetition throughout history (Bourdieu 1977). These local constructions are so ingrained that they become a saturated and stable system over time, and may be experienced as the objective reality underlying subjective practices - as 'just the way things are' (Bourdieu 1990). 
Second, field is a setting where individuals and their social positions are located, and they contain site-specific doxa (Hilgers and Mangez 2015; Thompson 2014). The field from this study is the UNPRPD country project in Uruguay, and primary players include the partnerships between the UN, government, civil society and consultancies working to change the surrounding national context. Each of these entities contains their own reality, making each perspective valuable to initiating change across social systems. Programme partners are micro-systems within their larger contexts, such as the UNCT as a substructure under the umbrella of the larger UN system. The government ministries involved are rooted in the larger political atmosphere. DPOs extend from the larger context of civil society and their particular mission (e.g. specialisation within disability organising). The UNPRD country project becomes a field once these entities come together for one shared purpose, with varying degrees of autonomy.

Partnering structures are intended to have low levels of autonomy from their broader affiliation mentioned above, but remain highly autonomous in their UNPRPD partnership role. Civil society or an OPD is selected to act as a channel to the larger disabled population that it represents. Likewise, the UNCT acts as an extension of the larger UNPRPD framework, as the UN operational system. This is not to say these external influences are simple and fit neatly into programming relationships. Structures represent groups with varying familiarity and, particularly with OPDs, a history of oppression. In other words, this UNPRPD field operates inside the broader fields of international development and those associated practices or hierarchies, the Uruguayan political field and the broader field of disability exclusion (Wescott, et al. In press) beyond the participants in this study.

Capital refers to the specific forces that direct power, particularly the historical and durable exchanges of resources (often between entities with similar capital value) that maintain hierarchies and norms across a given field (Bourdieu 1986). Bourdieu states that the processes between structures are defined by capital exchanges, and the capital transactions determine the difference between structures that position social hierarchies (Bourdieu 1986, 1987). That is, more capital leads to more powerful positions, and the absence of capital is associated with low influence and therefore little power behind the forces directing social systems. Social research categorises capital into various forms: economic, social, symbolic and cultural (Bourdieu 1986). Cultural capital is further divided into several sub-categories: institutionalised capital, which refers to the concrete qualifications of power, such as a driver's license or college degree ('she went to Harvard'); objectified capital, which refers to objects that contain meaning and status, such as designer shoes ('she dresses like a Harvard woman'); and embodied capital, which refers to understandings, opinions or ideological views expressed through particular attributes of personality, skills or voice held by individuals and groups ('she sounds like a Harvard woman') (Bourdieu 1986). The possession of these types of power relate to the ability to instigate, track and understand structural changes that underpin social systems. People with disabilities have experienced barriers to education, which results in high unemployment (United Nations n.d.). In this small example, the withholding of cultural capital acquired by formal education leads to a lack of economic and social capital generated from affiliation to legitimate institutions. These barriers are 
reflected in population data worldwide. The lack of capital over time perpetuates systematic exclusion from meaningful participation in social life. Capital provides a framework to understand the initiation of capital exchange between hierarchically opposite structures in the UNPRPD country projects.

The experience of the individual must be viewed in relation to structural forces and therefore is best understood through Bourdieu's habitus. Bourdieu captures much of the intangible barriers to inclusion through habitus, seen as the reflection of history through individuals and the intergenerational transmission between social structures and social life (Bourdieu 1990; Edwards and Imrie 2003). The individual is considered an embodied representative of their surrounding structural values, attitudes and behaviours (Bourdieu 1984), and therefore a conduit to structures targeted for development. Habitus can be highly nuanced for each aspect of the person including country of origin, educational background, family structure and innumerable other variations. However, what matters in the case of this research is the UNPRPD approach to include key representatives from each partnership as proxies to their larger structural embodiment, relying on individual habitus to initiate meaningful change.

This research was interested in the changes made in all key theoretical areas as a result of the UNPRPD project's efforts to positively enhance disability rights. While Bourdieusian concepts are not static, the concept of hysteresis ties together the experience of change in the habitus-structure relationship. Habitus and structures are malleable and can be sensitive to significant change in one side but not the other. Hysteresis is defined as the disruption to an individual's experience when internal (habitus) and external (structures, doxa) states become misaligned. (Bourdieu 2000; Hardy 2014; Strand and Lizaardo 2016). Based on the UNPRPD approach to engage key people within large systems and expose them to disability rights, hysteresis helps to understand how participants make sense of their experience in the UNPRPD project and what it means for their structural affiliations. More broadly, the concept of hysteresis is instrumental in making sense of a rapidly changing world comprised of structures that do not change at the same pace of the populations it serves, and will be relevant for future social research.

\section{Project background}

The UNPRPD project in Uruguay had three primary lines of work or, as the project termed them, 'pillars' of work. The first pillar focussed on universal access to health (CRPD article 25), specifically access to sexual and reproductive health in young people with disabilities. The second worked to address Gender-Based Violence (GBV), supported in CRPD articles 6 (women with disabilities) and 16 (freedom exploitation, violence and abuse), primarily through research and improvements to the national GBV intake protocol. Finally, the project set out to gather baseline data and map out services available to persons with disabilities (CRPD article 31: statistics and data collection). After the project was well underway, the project provided additional support to a working group of seven different government institutions towards developing a common disability assessment system, rather than the seven 
different assessments currently in use. Further, the UNPRPD seeks to increase the capacity of all stakeholders by establishing working relationships between government and civil society beyond the project.

The United Nations and Uruguayan government representatives have a longstanding relationship in development. Several participants joked that the country is so small that the two institutions often swap the same people and share a strong familiarity between practices. Learning the 'rules of the game' was very different for the civil society organisation selected to represent people with disabilities in Uruguay. The Alianza (also called the Alliance), an umbrella organisation of parents of people with disabilities and service providers (at the time of interviews, there were no OPD member organisations), operates on a voluntary basis, and does not have sufficient funding to offer salaries or formal positions. Many of the representatives work a full-time job in addition to their organisational role. This key difference in structural composition will be explored further in the discussion section.

\section{Methodology}

Initiating structural change is difficult, particularly, when the roots of disability exclusion are built into the fabric of social life. The aim of this research was to engage with individuals tasked with making change, and ask which events resulted in a significant shift towards realising the rights of persons with disabilities as a result of the UNPRPD project. A qualitative case study methodology provides a rich and varied context, which aligns with the UNPRPD programmatic framework to address local needs (UNDP 2016). Semi-structured interviews with the Most Significant Change Technique (MSCT) used open-ended questions to generate targeted reflection, while breaking away from traditional milestone-based metrics. All interviews were conducted during a field study visit in June 2019 at various locations in Uruguay.

The MSCT, which was created to capture data across different roles in complex organisational programmes, has proved useful in disability-inclusive development (Davies and Dart 2005; Quilliam and Wilson 2011). The use of MSCT to generate narratives across stakeholder groups allowed for standardised interviews, despite the differences between groups. Each participant answered the same six questions, generating insights from their respective organisational perspectives.

Four categories of stakeholders were interviewed in this study: UNCT representatives, government officials from participating ministries, organisations within the civil society organisation selected to support the UNPRPD project, and hired consultants. Purposive sampling was the most appropriate approach to ensure all participants had some role in the UNPRPD project. For example, the case study was not open to all civil society organisations or those promoting disability rights; rather, the inclusion criteria limited sampling to only organisations engaged with the UNPRPD work in this study. The same is true for government and UNCT participants. Government representatives from ministries outside the scope of the project were excluded from this study, as well as UN representatives. All stakeholders engaged in the project met the inclusion 
criteria, meaning that the sample only featured participants who could speak with insight and authority on the relevant project. All participation were voluntary and scheduled with the support of the UNPRPD project coordinator on site.

After all interviews were conducted, the data were analysed using Interpretive Phenomenological Analysis (IPA). The primary aim of IPA is to derive meaning from individuals' perceptions of a given phenomenon as evidence to make informed claims about the phenomenon itself (Smith et al. 2009). The UNPRPD programme operates globally, while also being flexible enough to address local instances of disability exclusion. Each country project is a different phenomenon, unique to that particular country's context and specific needs of people with disabilities. IPA, while criticised for its overdependence on subjectivity of interpretation, aligns with the purpose of including stakeholders that represent distinct expertise and experience related to local disability exclusion. As seen in Bourdieu's structural positionality and theories of capital-driven divides, stakeholders were chosen based on their autonomous affiliations to bring their perspectives together, bridging the gaps between groups. Based on the UNPRPD programme design, IPA analysed the meaning and context of individual responses, keeping in mind diverse perspectives of each structure. In this study, a subjective interpretation was necessary to faithfully represent each participant from their stakeholder perspective rather than analysing for concrete or objective statements.

The critique of researcher subjectivity in IPA was recognised in preparation to analyse the data. Smith et al. (2009) provide strategies for analysis to increase rigour and reduce bias. IPA involves researcher interpretation while calling for the data to be handled in a way that works to preserve the meaning in participant interviews. Thus, IPA provides a general protocol to process and handle data by first reading the transcripts in full for clear understanding, coding interviews for themes, connecting the themes as they relate to each other and repeating with all interview transcripts in the same fashion before proceeding with the analysis (Smith et al. 2009). Interpretation of participant responses takes place at only two points in the data-handling process: identifying themes and conducting the written analysis. Accordingly, this research implemented the method following IPA recommendations (see Fig. 1).

\section{Coding and themes}

Each interview was coded as a single case, beginning the process of coding and thematic identification anew with each of the interviews. Most participants discussed the same issues from various perspectives, laying the foundation to identify the emergent themes. Themes were easily determined by the synergy between the different actors and their reflections on the project. In this way, even though reading the 20 th interview made clear which themes were emerging as significant in line with the trends of the previous 19 , the later interview was still analysed in full in order to unearth any additional themes. 


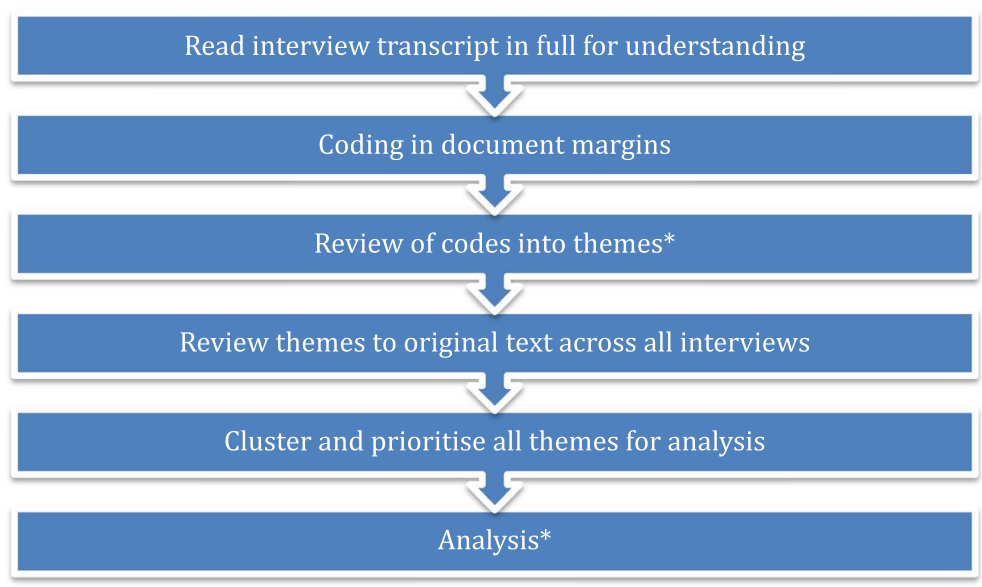

Fig. 1 This figure shows the stages of data handling for each interview transcript; stages 3 and 6 (each marked by an asterisk) indicate points in data handling with researcher interpretation

\section{Findings}

\section{Interview responses}

Few participants shared a complete story in response to the MSC central question. Many described the conditions of the project, along with challenges or their reflective thoughts on change and improving the lives of people with disabilities. In response to the interview prompt, 'From your point of view, describe a story that illustrates the most significant change that has resulted from the UNPRPD project in Uruguay at this phase of implementation', participants ranged from declining to answer, describing the challenges and sharing positive aspects of the project; only 4 of the 22 participants offered a complete story. The word 'change' was met with reservations on the part of participants and created a sense of caution around claiming concrete change. Many participants evaded specific statements concerning change when answering the question by making vague comments such as, 'We have made a big step', 'major contribution', or 'we have some key achievements' while also reporting the need for 'real change'.

Nearly all participants gave mixed reactions during the interview. For example, PG5 said:

If this ends up being plans that never end up being implemented - it can be positive, or it can be very, very negative. It can generate expectations. Then if later you want to implement something like this, people won't trust you. Have to implement at least some of the objectives, at least enough so people can trust you.

Moreover, the same participants expressing frustration in response to one prompt would provide hopeful or positive project feedback to a different prompt later in the interview. Likewise, some participants answered the prompts with 
thoughts about positive change, but they later shared concerns and unmet expectations. Based on the trend in participant responses, the interviews were analysed for themes across the whole conversation rather than scrutinising answers to any given question in isolation.

Participants generally felt the project had strong objectives and the UNPRPD approach to programming was valuable; however, change was difficult to identify or commit to. PG3 shared, "[That is a] really difficult question-not yet. I think we are in the point in the process of wrapping up, but there is nothing-I would love to hear what other people have said'. PUN16 from the United Nations articulated their response to change, saying, 'That is not the objective of the projectthat has to be expressed as improving access to disabled people, but we all know, in 18 months, we will not be able to implement the change'. Similarly, PG10 who had discussed many positive aspects of the project during the interview, the topic of change was still tentative:

The project in the UN has helped with the sexual and reproductive health, concepts for diagnosis, training - but it doesn't cover the more specific aspects... We made theoretical progress without having real things to offer - like rehab in health. Can have all the theory, it is not only about the technical support.

Alternatively, change was described more broadly as seen from PCS7, who noted, 'This is a cumulative thing. I'm not sure if there is an event, but the whole set has positioned the topic of disability in the public agenda'. Each of these participants from a range of structural perspectives shared contributions and achievements of the project. However, many of the interviewees answered the questionnaire by offering their overall reactions to the project in place of a story.

The subsequent interview questions respond to the story of change that the participants initially identified. In the absence of a story, these queries became a tool for participants to reflect on and describe their experiences and reactions. Interestingly, while change was difficult to identify when prompted directly, participants were much more comfortable discussing the significance of the project. Based on participant responses, what the project actually did was establish the problem, engage actors with personal and professional growth, and increase the visibility of disability rights.

Many participants reported the significance to be personal, despite not considering their own paradigm shift as 'real change'. PUN14 described how the project has influenced her daily operations and access considerations:

For me, it was a milestone. It was like, before and after. I think even, I am used to working in the frame of human rights, and the stories that she had (in the inception activity), and shared with the audience. It really touched me. This was the initial milestone. Other parts of the project that touched me - I will show you (shows her new business cards with Braille text)... Now I make my cards, thinking about persons with disabilities. It is a small detail, but that that is the way this project touched me, I changed some part of my life - my cards. This is the personal change I have made. 
Later, she described how this change in individual behaviour became structural: 'For the first time, I had to be very sincere. For the first time, we at the office rethink about the issues that our public events, for example, if they were accessible for everyone'. PUN17 reflected,

As personal experience, I learned a lot about persons with disabilities and how to act when you are, we have... all my instinctive actions are not always right. With blind people, I have to talk and not just act. That has increased my capability to have relations with persons with disabilities.

Many participants reported a change in their perception along with destigmatisation, even normalisation of disability in daily life. While these individuals were all from the United Nations or government structures, the participants did not always recognise themselves as agents of change with a new paradigm, despite their position as key stakeholders.

The magnitude of disability exclusion is overwhelming for any individual structure to resolve. Many of the government actors assigned to multiple projects addressing disability rights shared a feeling of loneliness or burden of carrying the depth of work required to achieve 'actual change'. The UNPRPD approach recognises the cross-cutting nature of disability rights and has worked to bridge individual silos for some participants, providing an empowering view of their role as agents of change and strategic planning. Thus, PUN14 stated:

If you look at the project, you could think ASSE (Administration of Health Public Services) would only participate in Theme 1, but it participates in all 3. So maybe that wasn't the objective of ASSE to participate in all three, but now we realise we are important actors in the project, because we will be incorporating it into our administrative records for our services. If this happened outside the project, we would not have been a part of the project. Or would have done it a different way.

The challenges facing individual focal points for large, powerful structures are present in the participants' reflections, particularly the investment in becoming more aware of disability rights. PUN14 later shared a beautiful sentiment: 'I think that people are-human beings are sensitive. The same that happened to me, perhaps in a different intensity, but all the people who were elected into this project. It is like a start point'. Fundamental changes to key actors were as present in participant responses as project reflections reporting no change, highlighting the discrepancy between changes actors sought to engage, and becoming the subject of change as a project outcome.

\section{Stories of change}

Few participants provided stories in answer to any of the MSCT questions. Four stories were collected in response to the UNPRPD project, and one additional story about another disability-related project. Two of the four UNPRPD-related 
stories described the inception event and the power of having persons with disabilities tell their own stories to an audience of government and UNCT members. PG3 said,

It is so very few times that persons with disability were heard, and have the chance to speak to government officials, to public, policy makers, and we created an environment. That was something that we - that gave these people the chance to think or be confronted with exclusion or with a different image. One girl was talking about all her achievements, and that helped break barriers of the vision of disability that is current. Charity and that. But I think that moment was very moving... It was a big ceremony and everyone was listening. So it was worth the risk. That doesn't change the life of anybody, but that was something. It was important.

Exposure to disability rights and engaging with key people were common themes across all four stories. Another story described a workshop held in Argentina with Mitch Loeb from the Washington Group, attended by some of the individuals assigned to the UNPRPD project. PUN8 said,

I think it is an activity representative of this need to join all the people working on - about - person with disability policies. They were open, they showed that they were open to hear about one possibility. They've known for 3, 4, 5 - 10 years about the Washington Group questions, but to go to discuss and go with an open mind. And try to reach a consensus. This process for trying to reach a consensus is just a great advance. To put them to dialogue, and to include the civil society voices is just a great advance. So I think that activity - the Washington Group activity was one of these key activities that showed this open mind, this perspective to work with the others.

The dialogue mentioned in this example was a key theme identified across all 22 interviews. The process of accumulating engagement across key individuals towards a common goal struck most participants as facilitating, or the first step towards 'real' change. The conversations between partnering structures were not an immediate win, but they did resonate with participants as significant. The fourth story demonstrates the importance of intergroup dialogue:

PC22: Yesterday I had a meeting with the women's institute that has always been uncomfortable with some questions. But I think it was the first time that some data were shared and put on the table so we can think together about the best strategy - and they are interested in the outputs of this work to be included in the national plan to make public policies - apart from having national data. I do believe that after working with the focus group, there is a well-known professional here in Uruguay that works on child abuse and trafficking, that after the focus group, she said to us, "Now I cannot unsee what I have now seen". There have been movements within people that when we share real situations of the weaknesses, the feedback we get from them, it's like - ok let's get together to find the best way. I think even though it may seem like something small, I think that some situations are being put on the agenda that had no vis- 
ibility in the past at all. I do believe there is intention and political will to think about how to go about it. I don't know when, but at least we do have the will.

Many participants felt the UNPRPD ToC, engaging key people in diverse structures towards effective state-wide change, was a successful approach to the project. Dialogue was said to have led to political will and hopes for change in the future. This hope was challenged by the changing values towards a new government across Uruguay and is discussed in detail below.

\section{Political changes}

Although Uruguay experienced political stability for 15 years prior to the UNPRPD project, it faced unexpected risk to its political stability during the elections in fall 2019. After the Broad Front established a leftist government that lasted from 2004 to 2019, elections returned power to the National Party after a narrow two-part vote on 27 October and 24 November 2019 (The Economist 2019). Participants' reflections of the UNPRPD project and identifying changes were affected by the unknown outcome to the elections four months prior to voting. Key project actors were unsure if the government participants would continue in their post or be replaced by a new government the following year. PG3 reported, '[There is a] real risk all the hard work they have done stays in a limbo. Risk of having to do it all over again'. Change felt possible but vulnerable to the political climate, as suggested by PUN8: 'Maybe it could be-will be used to improve the public policies. I am speaking conditionally because there will be the election in October/November, so we don't know who is taking in this key input'. Thus, political changes created uncertainty regarding the future implications of the project.

Several participants shared their support for structured engagement and dialogue as a pathway to realising disability rights in Uruguay, however, they also recognised several limitations once the political position of government partnerships was under threat of change before the project's end.

Participants from across the project said,

PC22: We are just a few people, but everyone is very protective of their own territory. So being able to think together, and these new spaces and figures that are painful, but I think this at least left this stage ready to start thinking. Since I've joined, it has made progress and in some ways gone back. Some data was heard, and other cases were pressured for the data to be public. I think now we can start thinking about doing something about this. It is a very complicated year for the country. I don't know if it was the best time to do it (the project), since in October we have elections. And that makes people feel unsure.

PG5: If this ends up being plans that never end up being implemented - it can be positive, or it can be very, very negative. It can generate expectations. Then if later you want to implement something like this, people won't trust you. Have to implement at least some of the objectives, at least enough so people can trust you. 
PUN3: Maybe we can make this other government be a part of this, and own the project - (it is) high risk.

PUN17: We think we are on the way. But the change of government is... everything.

Further concerns over solidifying the project to withstand the broader political changes altered the perception of the project's achievements. PUN14 said, 'We don't have the solutions, but at least we started the awareness'. PG20 stated, 'What I would like in this project in the remaining time, our own project becomes more visible-make the impact more visible-so people get to know about it-we need to have made a difference'. The project achieved not only the objectives laid out in the project proposal, but also made strides towards a systematised disability determination assessment across key sectors. While the project followed through on the targets set during its inception, participants broadly felt the mission had not been achieved. Activities such as research, trainings and established connections around a common framework began to feel insufficient as the political climate changed over the project's duration. Many participants commented on the distinction between 'theory and practice'. PG5 stated,

Regarding the other projects, we still don't have an output that is used in practice. We don't have anything in practice yet. The only thing I can think of, GBV, consultants gave information about how it is conducted at a national level. So, we have done some work, but still a lot to be done.

Nearly all participants hoped for some concrete and durable changes to withstand the possible change in government, which was an unforeseen consideration at the time of project planning.

\section{Discussion}

Interview data from the UNPRPD project in Uruguay are discussed below through the lens of Bourdieu's theories.

\section{Capital and context}

Bourdieu's capital, or the underlying forces driving social dynamics, is a tool to interpret the stakeholder interactions and processes designed to ignite structural change by the UNPRPD. The group held meetings in various government or United Nations buildings, around a conference table, scheduled at regular intervals and followed formal agendas, reflecting an unprecedented dedication to the topic of disability rights. Bourdieu recognised the significance of this type of legitimised procedure as the creation of opportunity (Moore 2014), and thus advantage over unstructured, unsystematic interaction prior to the UNPRPD engagement and programmatic framework. In line with the theory, several participants saw the value of formality in the same way Bourdieu described, noting the process of solidifying disability development conversations within places of national authority led to 'putting disability on 
the agenda'. Further, the processes took place around what Bourdieu notes as meaningful objects (objectified capital), such as grand conference tables in a government building reserved for project participants to sit around and engage across stakeholder lines. Bourdieu's connection between abstract and tangible is seen in the UNPRPD partnership building, which is difficult to capture in traditional metrics. For example, the Alliance had no physical space to conduct operations. This lack of objectified capital, or tangible resources that facilitate or hinder participation, contributed to the quality of engagement between the Alliance and the UNPRPD tripartite approach. These contrasting examples are helpful to see how objectified capital according to Bourdieu can help or hinder the processes underlying the UNPRPD project goals, evidenced by the meeting rooms as a means of establishing connection that is so essential to the partnership approach. In other words, the presence of cultural capital struck participants as a noteworthy step towards establishing disability rights as a legitimate agenda item for the business conducted in government and UN buildings.

In addition to the impact of physical space and formal procedure in the project, Bourdieu's field theory makes sense of the landscape where capital was mobilised. Thompson (2014) relays Bourdieu's work, stating: 'Like a force field, a social space operates semi-autonomously. It is a human construction with its own set of beliefs, which rationalize the rules of field behaviour-each field has its own distinctive "logic of practice"" (p. 68). From the data, participants often reflected on the establishment of a metaphorical 'seat at the table' for focal points who previously worked in silos. Bourdieu's shared understanding behind field-specific practice is called doxa, distinct from other fields that participants may interact with. As such, each focal point was there on behalf of the broader government ministry, UN agency or population of people with disabilities, and solidified a new set of norms comprising structural proxies. The UNPRPD established a formal protocol to include a range of stakeholders and gain consensus among members for project activities, always guided by the CRPD as their compass. While government focal points remained positioned in their governmental role throughout the project, discourse and decisionmaking procedures were open to all stakeholders while in the UNPRPD context. The project scheduled an onboarding period to ground all institutional representatives in the disability rights paradigm and establish expectations for project conduct emphasising the engagement of persons with disabilities. Much like Thompson described, the UNPRPD was an intentional construct, with field behaviour guided by the specific belief in the CRPD. The production of a sub-field for project interactions was reinforced by scheduled recurring meetings, exposing and normalising the consensus approach to participation regardless of their affiliating position. In other words, the partnership approach initiated a Bourdieusian sub-field to have legitimised discussion around disability rights in the Uruguayan context.

Establishing a sub-field created the opportunity for engagement, however, capacity issues with the selected civil society organisation altered the role of people with disabilities in the project, resembling an objectified capital (or tokenism) of those who were available to the project. While the programme design called for equal partnership between rights holders and duty bearers (UNDP 2016), the lack of OPD membership throughout the process changed the utility of the few individuals with disabilities engaged in the project. Interview responses remarked on the significance 
of personal testimonies by those individuals with disabilities in the inception activity and health training sessions, particularly, the rare opportunity for high-level government officials or health providers to see and hear from successful individuals with disabilities. These select few conveyed the ethos of the UNPRPD project to outsiders through their physical presence, or as objects for paradigm shift (cultural capital). This can also be seen as symbolic capital on behalf of the UNPRPD, where the project conveyed the presence of a regulatory partnership many participants felt did not meaningfully exist. Whether seen as objects or symbols, disabled bodies were reclaimed in public spaces to advocate for rights, while the internal operations lacked meaningful OPD membership within the Alliance.

Embodied cultural capital requires ongoing, direct exposure to a new set of ideas or norms to integrate into one's habitus (Bourdieu 1986), illustrated by the UNPRPD establishing a sub-field with consistent reinforcement of the disability rights paradigm. This creation of a new field and new 'rules' (or doxa) with prolonged exposure made the participants acutely aware of the constructed social dynamics that resulted in and perpetuate disability exclusion in Uruguay. The shift from regular exposure to embodiment can be seen in the government and United Nations participant responses describing a fundamental change in practice, a fresh start, or a newfound conviction. PG19 said, 'I've been working on this for more than 30 years... It was difficult to talk about this, but now it is difficult to stay silent'. Many participants shared this shift from disability invisibility to self-driven advocacy in the same way Bourdieu described the construction of new internal (habitus) and group (doxa) norms through direct exposure. As such, the UNPRPD group dynamic created a circular reinforcement whereby individual paradigm shifts were regularly reinforced by the project environment.

Many participants discussed disability rights issues beyond the UNPRPD project. Several focal points on the project were also assigned other tasks related to disability as a central expert in their structure. This experience enabled what the UNPRPD calls 'duty bearers' (United Nations Development Programme 2016), or individuals with the capital to action programming, to immerse themselves in a new worldview and become more oriented towards disability inclusion. In a sense, this reorientation of their perspectives made it feel as though disability was suddenly everywhere. The majority of participants reported a sense of urgency in achieving change and addressing the barriers imposed on people with disabilities, and they even expressed the intention to address such issues beyond the scope of the projects they were working on. This deeply embedded change in habitus is further evidenced by their unsuccessful attempts at applying practices from their previous habitus into the field of the UNPRPD: 'We feel impotent trying to find the real mechanism to give them a voice and protect and empower them. It's hard'. The notion that a real mechanism did not include any of the long-held processes signified the presence of a new, shared habitus for participants in the same way Bourdieu recognised the possibility of individual change to such an extent that a habitus begins to mismatch their newly acquired internal and well-established external states, challenging the implementation of a new normal (see hysteresis below).

Based on the data, the project did not reach persons with disabilities in the single phase of programming as a primary outcome. Going back to the social model 
of disability, what the project did was reorient powerful actors towards a disability rights paradigm rather than changing (e.g. fix, alter, assimilate) individuals with disabilities. This outcome has positive implications for sustainability, as embodied capital alters the lens through which people practise in the positions they occupy. Byrne (2017) argues the value of this internal shift by placing it within the context of Bourdieu's theory of habitus. She states, 'Even when the dominant cultural arbitrary (social construction of disability inequality) is challenged, it will not be until the habitus of the non-disabled population is effectively transformed via the internalisation of "new" dispositions that we will see substantive change' (p. 12). The data provide evidence of a shift in habitus by the non-disabled representatives from dominant structures in the UNPRPD (though not the Uruguayan population), despite the majority opinion that 'real' change has not been achieved.

The final of Bourdieu's capital considers the economic distribution, and specifically the impacts of uneven distribution of resources between groups. In this case, the costs involved with civil society involvement was challenging for historical reasons. Bourdieu discussed the ease of interaction when a relationship is cultivated with ongoing resource exchanges over time (Bourdieu 1986), which was seen in the United Nations and government's long-standing working relationship. Salaries and approved lines of work were budgeted within the organisations to account for the time required for participation in weekly meetings and project activities (economic capital) without supplementing with direct payment for each focal point's time. This was not true of civil society, which lacked a mechanism to support the cost of participation, creating a demand for voluntary commitments from individuals in addition to their income-earning jobs or care responsibilities. Using Bourdieu's terms, the economic power between dominant structures protected the individual actor's role in project participation while supporting the cost of that contribution, however, that was not true of the most subordinate structure. Small grants were available for project expenses but did not reach far enough to fund salaries or the 'meaningful participation' outlined in the CRPD. Participation on 'equal' volunteer terms is inequitable based on vastly different capacities between structures, and created a barrier over time between the UNPRPD sub-field interactions 'at the table' and engagement with the member body of the Alliance.

\section{Habitus reconstructed}

Research has provided ample support for the concept of habitus. That said, the literature addressing mismatched habitus is far harder to find. Bourdieu's concept of hysteresis captures a mismatch in individual habitus and their field or social space of interaction (Bourdieu 2000; Hardy 2014). According to Dirk and Gelderblom (2016, p. 345), 'the habitus can adjust to new conditions, but that this adjustment has limits... hysteresis results when the habitus is affected by fundamental change in the field'. As previously described, habitus and structure are interdependent and relational. The currently available research describes a mismatch in a singular way: a static habitus confronted with a changed environment (Barrett 2018; Bourdieu 1990; Dandoy 2015; Dirk and Gelderblom 2016; McDonough and Polzer 2012). 
Nonetheless, this research evidences the same phenomenon in reverse. In the case of Uruguay, a new habitus was formed among participants to a disability rights paradigm, situated in the same overall national context from which they developed their previous habitus. In Bourdieusian terms, the project became a space to practice their newly acquired dispositions without a tremendous mismatch between habitus and the UNPRPD project sub-field. Everyone in the project contained the same, newly developed sense of disability rights that was not evidenced in broader society. Many of the participants felt a mismatch in habitus to their 'home' structures (e.g. government ministries, medical offices, schools), which had previously held more synergy.

Although a change in environment did occur in silo by establishing the UNPRPD as a sub-field, participants remained officially affiliated to their respective structures while contributing to the project (autonomous). As evidenced by interview responses, the project was highly valued despite the frustration for 'real change'. From a Bourdieusian lens, the UNPRPD was a mini-field, temporary and constructed, shared with a group over a common doxa and thereby matching their new habitus to their environment. They collectively constructed their group and norms around the rights of persons with disabilities. Bourdieu noted the culture shock experienced by individuals when they step outside of their environment of shared understanding and into social systems that do not align. For UNPRPD participants, their home structures did not undergo the same transformation, and those internal changes were not in practice across systems in Uruguay. For Bourdieu, the larger government ministries and UN agencies would have adopted the same paradigm shift and priorities of the UNPRPD with little friction in implementing disability rights across the country to avoid hysteresis. While Bourdieusian methodology does not provide a distinct habitus threshold, or tipping point from one set of norms and beliefs to another, previous research has attributed similar reactions to fundamental change as those experienced by the UNPRPD focal points (e.g. Barrett 2018; Graham 2020; McDonough and Polzer 2012).

The adoption of a new reality-one where the exclusion of persons with disabilities is recognised as an objectively true by product of society's social constructions-was evident in participant responses, such as '.. all the people who were elected to this project. It's like a start point'. Having undergone a paradigm shift towards a disability rights perspective, participants gained a new vision for the future of Uruguay. Bourdieu theorised about habitus integrated deeply as to be automatic and frame that individual's disposition and conduct (Bourdieu 1990). Disability rights were deeply embodied with no evidence of nostalgia for the participant's previous norms, as if they were wholly replaced. Instead, several participants expressed a debt owed to people with disabilities in Uruguay based on the consequences of previous practices. The participants, particularly those from the government, embodied and integrated a disability rights paradigm beyond the scope of their role in place of their previous habitus, while remaining in the same structural position in an unchanged field.

Emotion according to Bourdieu, including the individual's experience of emotional upset in hysteresis, has been described as resting upon 'a durably installed felt sense of place... (which) reflects an intuitive grasp of one's position within the encompassing social environment' (Barrett 2018, p. 38). Thus, the emotional 
experiences of individuals are rooted in a relationship between the internal state of habitus and the external conditions that surround them. In the case of the UNPRPD country project participants in Uruguay, the emotional tension and contradiction shared during interviews using such terms as feeling 'lonely' or 'impotent' to achieve 'real change' illustrate the experience of hysteresis. Most participants expressed contradictory views on the work, as seen in Table 1. Highs and lows demonstrate a new attitude towards the mission of disability rights, even though mismatched to an environment now perceived as stagnant.

Due to the disruption between the habitus and structure of participants, their habitus will remain unsettled until 'a radical transformation of the social conditions' (Barrett 2018; Bourdieu 2001, pp. 41-42). These participants, who have become agents of change, appear to remain in their new disability paradigm. As several participants observed, 'I cannot unknow what I have learned'. The altered habitus equates to what Bourdieu saw as a durable change among decision makers in dominant social structures across Uruguay.

\section{Hysteresis and political change}

While the UNPRPD altered the habitus of participating actors, Uruguay faced political changes during the November 2019 election. The hysteresis described above was further compounded by the risk of radical change in governance, destabilising the positions of power held by participants. Interview responses posed the question 'If the most significant change occurred within individuals in positions of power, how much is internal change worth if those positions are replaced? In a tripartite approach with low capacity in civil society and threat to the stability of government, the project faced major barriers to structural change and transfer of responsibility from the UNCT as the project approached the end of its own timeline. The fundamental distribution of power leveraged by the programme changed when the remaining time and capacity (or for Bourdieu, capital) of individuals within institutions came to a close. This is especially true from a Bourdieusian perspective whereby a governing institution held power for 15 years, solidifying processes and procedure into a durable rhythm of practice that faced upcoming change. The system was no longer predictable and new norms would take their place; thus, larger field changes created a new layer of tension between individuals, social space and reactions to the project. With a more conservative government elected to meet the changing needs of the public (concerns such as safety in dense cities, according to participants), the uncertainty of project uptake with a new government inflated pressure to achieve radical change for Uruguayans with disabilities. For Bourdieu, embodying and legitimising change has a time component. Long-held exclusion is woven into the fabric of policy, practice, society and within the individuals that action the constructed norms. There was a sense of 'running out of time', or as PUN8 stated, 'there (was) no political time' to realise the newly integrated disability rights paradigm. Framed with Bourdieusian terms, the increased pressure to enact a new practice and reflect the disability rights paradigm was aggravated by field changes that further mismatch 


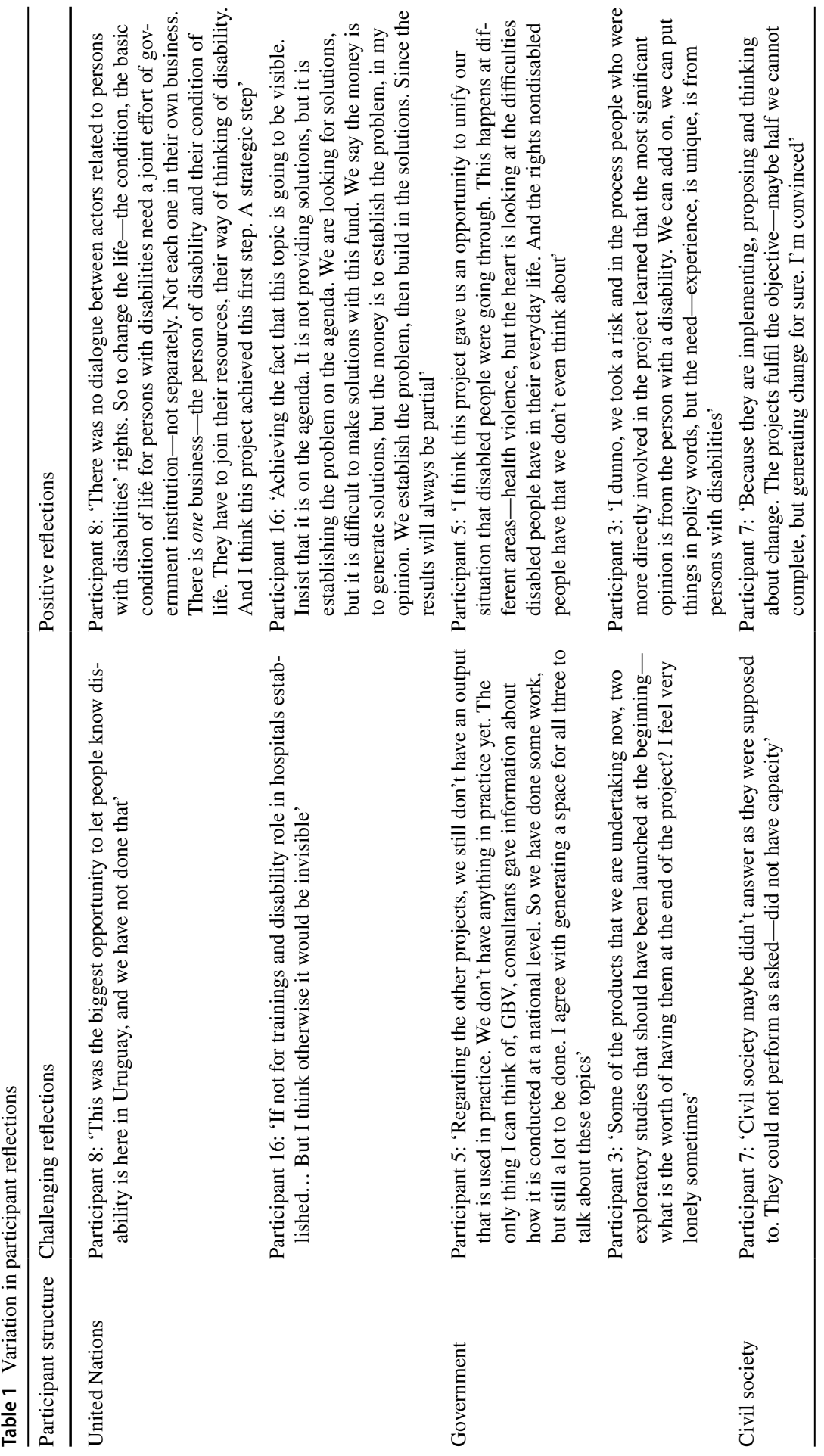




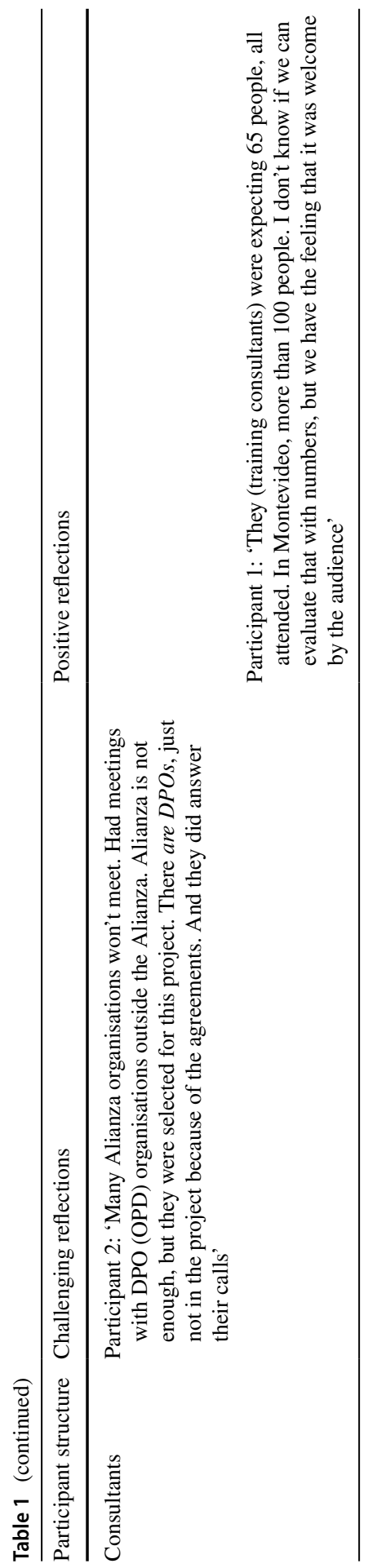

SN Social Sciences

A SPRINGER NATURE journal 
participant's habitus with the practice contained in Uruguay's social field undergoing an ideological shift.

\section{Conclusion}

Disability-inclusive development at a global scale is difficult to demonstrate with traditional programming, leaving much of the development process and outcomes unknown. Exclusion and inclusion express differently in diverse cultures and contexts, limiting any universal or fixed targets designed to monitor the effects of programming. In an effort to better understand human rights development in the context of disability, Pierre Bourdieu's theories capture abstract and concrete shifts in the underlying forces that perpetuate exclusion.

For some participants in this study, perceptions of the project's success became dependent on the upcoming elections. Participants had several concerns. Would the new government adopt the research and priorities generated by the project? How will new leadership adopt disability rights as a priority without the engagement and dialogue process facilitated by the UNPRPD? The UNPRPD project is a microcosm, a phenomenon. The aim is to transfer its processes and outcomes to local and mainstream structures in order to bring about wide-ranging social change. As of July 2019, the Uruguay UNCT did not plan to reapply for a second round of programming, concluding the project in March 2020. Is 2 years enough to create sustainable change, durable to withstand overlapping social changes such as a new government? Previous sections described the value of having inter-institutional engagement and bringing a unified approach to implement the CRPD - this is why dialogue is so crucial. But if the potential for a new government creates such high risk, how much is dialogue worth? If the projects rely on current conditions, how can projects be developed that are durable against unexpected social change?

Many participants embodied the ideals of the CRPD, recognising persons with disabilities as rights holders and experiencing discomfort at realising their new set of values were yet to be fully implemented across multiple levels of social life in Uruguay. The UNPRPD altered habitus in key project representatives, creating the sense of beginning an entirely new chapter as the project came to a close. Bourdieu's theory provided the context to underpin a broad range of participant reflections, diverse field dynamics and critical learning points for future disability-inclusive development projects.

\section{Limitations}

Interviews were conducted during one month of the 2-year project timeline, nearing the end of implementation. Follow-up research may provide insights into changes made by the UNPRPD after the project is completed, particularly after the change in government. 
Acknowledgements This article used Cambridge Proofreading for editing services. Many thanks to George S. for the helpful input on formatting, reference style, word choice and UK spelling. These services were funded by the authors. We also wish to thank the UNPRPD for the support and invitation to conduct this study.

Funding The author received funding from the Irish Research Council to conduct high-quality research and expand the available knowledge on this topic. We wish to extend our gratitude to the Irish Research Council for the opportunity to illuminate the work of the UNPRPD for future development initiatives.

Data availability Manuscript contains data that will be available upon reasonable request.

\section{Declarations}

Conflict of interest The authors have no conflicting or competing interests to declare.

Ethical approval This case study design and interview methods have been implemented in a previous postgraduate thesis study as well as the research presented, both having received ethical approval.

Informed consent Informed consent was provided in both English and Spanish, and all participants were offered interpreter services for effective communication. Accommodation for disability access was offered to ensure participation of all eligible stakeholders of the project. This publication has been approved by all co-authors.

Open Access This article is licensed under a Creative Commons Attribution 4.0 International License, which permits use, sharing, adaptation, distribution and reproduction in any medium or format, as long as you give appropriate credit to the original author(s) and the source, provide a link to the Creative Commons licence, and indicate if changes were made. The images or other third party material in this article are included in the article's Creative Commons licence, unless indicated otherwise in a credit line to the material. If material is not included in the article's Creative Commons licence and your intended use is not permitted by statutory regulation or exceeds the permitted use, you will need to obtain permission directly from the copyright holder. To view a copy of this licence, visit http://creativecommons.org/licen ses/by/4.0/.

\section{References}

Barrett T (2018) Bourdieu, hysteresis, and shame: spinal cord injury and the gendered habitus. Men Masculinities 21(1):35-55

Blackmore T, Hodgkins SL (2012) Discourses of disabled peoples' organisations: foucault, bourdieu, and future perspectives. In: Goodley D, Hughes B, Davis L (eds) Disability and social theory. Palgrave Macmillan, London, pp 70-87

Bryne B (2018) Dis-equality: exploring the juxtaposition of disability and equality. Social Inclusion 6(1):9-17

Bourdieu P (1977) Outline of a theory of practice. Cambridge University Press, Cambridge

Bourdieu P (1984) Distinction: a social critique of the judgment of taste. Harvard University Press, Cambridge

Bourdieu P (1986) The Forms of Capital. In: Richardson J (ed) Handbook of theory and research for the sociology of education. Greenwood, Westport, pp 241-258

Bourdieu P (1987) What makes a social class? On the theoretical and practical existence of groups. Berkeley J Sociol 32:1-17

Bourdieu P (1990) The logic of practice. Stanford University Press, Stanford

Bourdieu P (1998) The state nobility: elite schools in the field of power. Stanford University Press, Stanford

Bourdieu P (2000) Pascalian meditations. Stanford University Press, Stanford

Bourdieu P (2001) Masculine domination. Polity Press, Cambridge 
Dandoy A (2015) Towards a Bourdieusian frame of moral panic analysis: the history of a moral panic inside the field of humanitarian aid. Theor Criminol 19(3):416-433

Davies R, Dart J (2005) The 'Most Significant Change' (MSC) technique: a guide to its use. https://www. mande.co.uk/docs/MSCGuide.pdf

Dirk WP, Gelderblom D (2016) Higher education policy change and the hysteresis effect: Bourdieusian analysis of transformation at the site of a post-apartheid university. High Educ 74:341-355

Edwards C, Imrie R (2003) Disability and bodies as bearers of value. Sociology 37(2):239-256

Graham H (2020) Hysteresis and the sociological perspective in a time of crisis. Acta Sociologica 63(4):450-452

Hardy C (2014) Hysteresis. In: Grenfell M (ed) Pierre Bourdieu: key concepts, 2nd edn. Routledge, London, pp 65-80

Hilgers M, Mangez E (2015) Bourdieu's theory of social fields: concepts and applications. Routledge, New York, NY

Krause M (2014) The good project: humanitarian relief, NGOs and the fragmentation of reason. University of Chicago Press, Chicago

Krause M (2017) The patterns in between: "Field" as a conceptual variable. Br J Sociol 69(1):1-18

McDonough P, Polzer J (2012) Habitus, hysteresis, and organizational change in the public sector. Can J Sociol 37(4):357-379

Moore R (2014) Capital. In Grenfell M (Ed) Pierre Bourdieu: Key concepts, 2nd ed, pp 65-80, Routledge

Quilliam C, Wilson E (2011) Literature review-outcomes measurement in disability services: a review of policy contexts, measurement approaches and selected measurement tools. Deakin University, Melbourne

Shakespeare T (2014) Disability rights and wrongs revisited, 2nd edn. Routledge, London

Smith JA, Flower P, Larkan M (2009) Interpretative phenomenological analysis: theory, method and research. Sage, Thousand Oaks

Strand M, Lizaardo O (2016) The hysteresis effect: theorizing mismatch in action. J Theory Soc Behav 47(2):164-194

The Economist (2019) Power shifts in Uruguay, without much fuss: riding the waves. https://link.gale. com/apps/doc/A624582224/AONE? $\mathrm{u}=$ nuim\&sid=AONE\&xid=054681c5. Accessed 19 Nov 2020

Thompson P (2014) Field. In: Grenfell M (ed) Pierre Bourdieu: key concepts, 2nd edn. Routledge, London, pp 65-80

United Nations (n.d.) Factsheet on persons with disabilities. https://www.un.org/development/desa/disab ilities/resources/factsheet-on-persons-with-disabilities.html. Accessed 25 Nov 2020

United Nations Development Programme [UNDP] (2016) UNPRPD strategic and operational framework. mptf.undp.org/document/download/15036. Accessed 2 Nov 2020

UNPRPD (2019) Our Programmes. http://unprpd.qburst.build/our-programmes-country. Accessed 20 Nov 2020

Wescott H, MacLachlan M, Mannan H (In press) The macropsychology of disability rights and structural change: using Bourdieusian analysis to understand stakeholder power relations. In: MacLachlan M, McVeigh J (eds) Macropsychology—a population science for Sustainable Development Goals. Springer, Cham

World Health Organization \& World Bank (2011) World disability report: summary. WHO Press, Geneva 